\title{
Mid-to-long term oncologic and functional outcomes of zero ischemia laparoscopic microwave ablation-assisted tumor enucleation for renal cell carcinoma: a single-center experience
}

\author{
Jiale Zhou ${ }^{\#}$, Xiaorong Wü, Jin Zhang, Jiwei Huang, Yonghui Chen \\ Department of Urology, Renji Hospital, School of Medicine, Shanghai Jiao Tong University, Shanghai, China \\ Contributions: (I) Conception and design: J Huang, Y Chen; (II) Administrative support: Y Chen, J Zhang; (III) Provision of study materials or \\ patients: Y Chen, J Huang, J Zhang; (IV) Collection and assembly of data: J Zhou; (V) Data analysis and interpretation: J Zhou, X Wu; (VI) \\ Manuscript writing: All authors; (VII) Final approval of manuscript: All authors. \\ \#These authors contributed equally to this work. \\ Correspondence to: Jiwei Huang; Yonghui Chen. Department of Urology, Renji Hospital, School of Medicine, Shanghai Jiao Tong University, Shanghai \\ 200127, China. Email: jiweihuang@outlook.com; cyh1488@163.com.
}

Background: Zero ischemia laparoscopic microwave ablation assisted tumor enucleation (MWA-TE) has been applied to renal cell carcinoma (RCC) treatment, but the mid-to-long term follow-up results are lacking. This study aims to evaluate the mid-to-long term oncological and functional consequences of MWA-TE in RCC treatment.

Methods: We conducted a retrospective analysis of 278 patients who received zero ischemia laparoscopic MWA-TE for RCC from March 2013 to June 2017. Peri- and post-operative data, renal functional and oncologic results were accumulated and evaluated.

Results: The median length of operation was $86 \mathrm{~min}$, with an approximate median blood loss of $50 \mathrm{~mL}$. The median estimated glomerular filtration rate (eGFR) prior to and 3 months post-operation was 90.6 [interquartile range (IQR), 65.2-116.0] and 83.6 (IQR, 52.4-114.8) $\mathrm{mL} / \mathrm{min} / 1.73 \mathrm{~m}^{2}$, the median eGFR of the latest follow-up was 87.4 (IQR, 67.7-107.1) $\mathrm{mL} / \mathrm{min} / 1.73 \mathrm{~m}^{2}$ and paired t-tests showed no significant difference between preoperative, post-operative and latest eGFR ( $\mathrm{P}=0.069$ and $\mathrm{P}=0.071)$. The median change in eGFR from before surgery to the latest follow-up was $-2.82 \mathrm{~mL} / \mathrm{min} / 1.73 \mathrm{~m}^{2}$. The median followup period was 39 months, and among all the patients, nine reported cancer recurrence or metastasis, the 3- and 5-year overall survival (OS) was $99.6 \%$ and 98.4\%, respectively, and recurrence-free survival (RFS) was $98.2 \%$ and $95.8 \%$, respectively.

Conclusions: Zero ischemia laparoscopic MWA-TE is considered a feasible and effective nephron sparing surgical technique for selected renal tumors, and is accompanied by a low perioperative complication rate and promising mid-to-long term oncological and functional outcomes.

Keywords: renal cell carcinoma (RCC); microwave ablation assisted tumor enucleation (MWA-TE); NSS; microwave ablation (MWA); partial nephrectomy

Submitted Sep 05, 2020. Accepted for publication Mar 12, 2021.

doi: $10.21037 /$ tcr-20-2846

View this article at: http://dx.doi.org/10.21037/tcr-20-2846

^ ORCID: 0000-0002-6998-7128. 


\section{Introduction}

Increasing numbers of renal tumors are diagnosed at an early stage without presenting clinical symptoms (1). Nephron sparing surgery (NSS) has been recommended and viewed as the golden standard for cT1aNOM0 and selected cT1bN0M0 renal tumors because of reliable oncological outcomes as well as better preservation of renal function than radical nephrectomy (2). For NSS, the Trifecta standard is widely-accepted by urologists. The advantages of this approach include negative surgical margin, better preservation of normal renal parenchyma and no post-operative complications (3). However, the method by which the Trifecta standard can be achieved during NSS has become a major concern. For this purpose, minimally invasive techniques including radiofrequency ablation (RFA), microwave ablation (MWA) and cryoablation have been widely applied to compact renal mass therapy worldwide (4). However, the percutaneous ablation techniques have shortcomings that include a higher possibility of incomplete ablation and greater damage to kidney through the use of contrast-enhanced computer tomography during follow-ups (5).

In 2003, Jacomides et al. introduced a procedure that included both thermal ablation and laparoscopic NSS, in the absence of a renal artery clamp (6). This procedure ameliorated hemostasis and decreased or even eliminated the warm ischemia time. Since 2011, we have been performing zero ischemia laparoscopic RFA-assisted tumor enucleation (RFA-TE) and MWA-TE at our institution. In 2015, we conducted a randomized clinical study that showed that RFA-TE had similar short-term oncologic outcomes, but better renal function preservation compared with conventional laparoscopic partial nephrectomy (LPN) (7). During further clinical practice, we found that MWA is more efficient than RFA for reaching ablation temperature (8). Studies from several institutions have demonstrated that the MWA-TE technique has similar short-term oncologic and functional outcomes compared with LPN and RFA-TE, but the sample volumes and follow-up duration were limited $(9,10)$. Here, we evaluated the mid-to-long term functional and oncologic results of MWA-TE in a study that might be the largest sample volume study in the urologic community. We present the following article in accordance with the STROBE reporting checklist (available at http://dx.doi.org/10.21037/tcr-20-2846).

\section{Methods}

\section{Patients}

This retrospective study included data from patients who received zero ischemia laparoscopic MWA-TE from March 2013 to June 2017. Patients with a single, sporadic, unilateral, organ-confirmed and pathologically diagnosed renal cell carcinoma were included in the study. The following exclusion criteria were applied: patients with multiple tumors on ipsilateral kidney, collecting system or renal vein invasion, previous renal surgery history of the operative kidney, or with other renal diseases (such as renal calculi, glomerular nephritis, etc.). Since this study focused on the oncological outcomes for MWA-TE, patients with benign pathological diagnosis were also excluded. The study was conducted in accordance with the Declaration of Helsinki (as revised in 2013). The study was approved by research medical ethics committee of Shanghai Renji Hospital, China \{ethics board approval number: Renji Ethics [2017]091\}. Informed consent was obtained from all individual participants.

Prior to the operation, all patients underwent abdominal enhanced computed tomography (CT) or magnetic resonance imaging (MRI), chest CT, and serum creatinine and hemoglobin $(\mathrm{Hb})$ measurements. None of the patients had pre-operative or intra-operative-suspected positive lymph nodes (N0) and none exhibited distal metastasis on the preoperative image (M0). The size, location and depth of the tumor was described using the R.E.N.A.L. nephrometry score (11).

\section{Surgical interventions}

All operations were conducted by highly experienced renal surgeons (YH Chen, JW Huang and J Zhang). The technique used for MWA-TE before ablation was similar to that used for laparoscopic RFA-assisted partial nephrectomy (LRAPN) as previously described (7). For tumors adherent to the renal hilum, the renal artery was isolated for potential clamping. After the tumor was localized and dissected, 1 to 3 cycles of MWA were performed lasting 2 to 8 min depending on the tumor size and depth. The MWA cycles were delivered with a 13-gauge antenna attached to the Evident Valleylab generator (Kangyou Medical Instruments, Nanjing, China), with a capacity to produce 45 $\mathrm{W}$ at $915 \mathrm{MHz}$ power. The tumor was enucleated mainly 

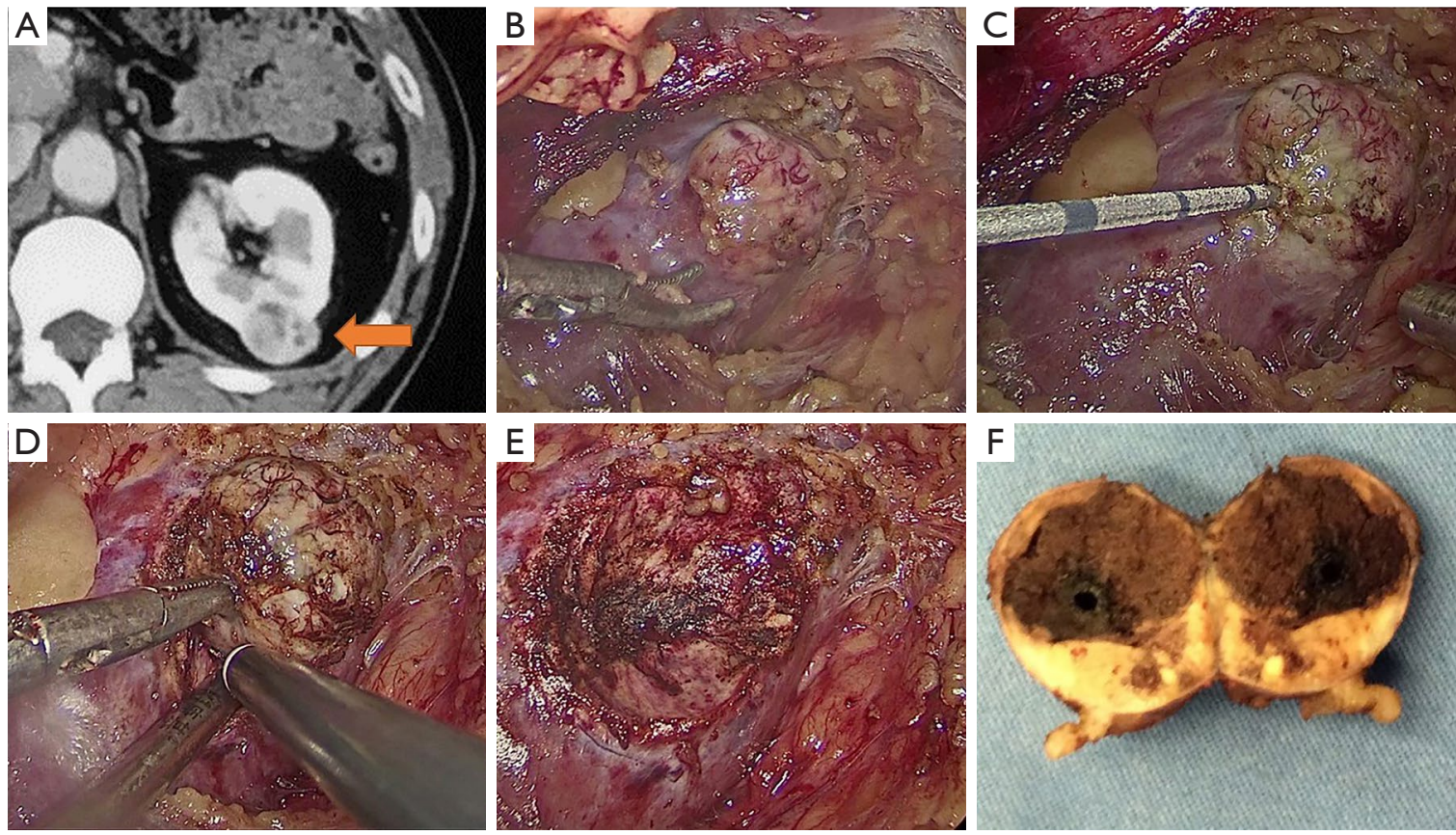

Figure 1 A typical case of zero ischemia laparoscopic microwave ablation assisted tumor enucleation for a cT1aN0M0 renal cell carcinoma. (A) Axial contrast-enhanced computed tomography (CT) images. Exophytic T1a renal tumor on middle third of the left native kidney (orange arrows). (B) The tumor was exposed under laparoscopy. (C) Microwave ablation electrode was placed at the basement layer of tumor. (D) The tumor was enucleated mainly via blunt and sharp dissection along the natural cleavage plane between the pseudocapsule and normal parenchyma. (E) Tumor bed bleeding was managed by monopolar or bipolar coagulation. The parenchymal defect was allowed to remain open. (F) Tumor sample.

by blunt and sharp dissection along the natural cleavage plane between the pseudocapsule and normal parenchyma. Tumor bed bleeding was managed using monopolar or bipolar coagulation. The parenchymal defect was allowed to remain open and a drain was kept in place toward the end of the operation. The tumor was dispatched for pathological assessment. Details of the surgical procedure are shown in Figure 1. The post-operative complications were monitored and recorded within 3 months after the procedure. Complications were recorded using the modified ClavienDindo classification (12).

\section{Pathological evaluation}

Standard hematoxylin and eosin staining, and the immunohistochemical analysis were performed to evaluate the histopathological characteristics, based on the 2010 Union for International Cancer Control (UICC) TNM classification and Fuhrman classification $(13,14)$.

\section{Follow-up}

The follow-up procedure after surgery in our facility included clinical visits, blood biochemistry studies, and imaging tests. The blood biochemistry studies included routine blood tests, renal function tests, and detection of other biochemistry markers included in the Memorial Sloan Kettering Cancer Center risk model for renal cells carcinomas (RCCs). Contrast-enhanced CT scans were performed 3 months after surgery for the detection of local focal recurrence and renal filtration function tests. Recurrence was described as any newly found enhancement $(10 \mathrm{HU})$ at 3 months in contrast-enhanced CT after surgery. During the follow-up, blood tests, abdominal MRI and chest CT scans were conducted every 6 months until 2 years and annually thereafter.

Post-operative eGFR was defined as the eGFR measured at the first follow-up 3 months after surgery. The eGFR was assessed, based on the Modification of Diet in Renal Disease Equation (15). 
Table 1 Baseline characteristics of patients undergoing zero ischemia laparoscopic microwave ablation assisted tumor enucleation

\begin{tabular}{|c|c|}
\hline Parameters & Value \\
\hline Age (years), median (IQR) & $57.0(40.0-74.0)$ \\
\hline \multicolumn{2}{|l|}{ Gender, n (\%) } \\
\hline Male & $222(79.9)$ \\
\hline Female & $56(20.1)$ \\
\hline Body weight (kg), median (IQR) & $70.0(57.0-83.0)$ \\
\hline Height (cm), median (IQR) & $170.00(159.25-180.75)$ \\
\hline No. hypertension (\%) & $113(40.6)$ \\
\hline \multicolumn{2}{|c|}{$\begin{array}{l}\text { Age adjusted Charlson Comorbidity } \\
\text { index (aCCl), } \mathrm{n}(\%)\end{array}$} \\
\hline 0 & $71(25.5)$ \\
\hline 1 & $66(23.7)$ \\
\hline 2 & $68(24.5)$ \\
\hline 3 & $51(18.3)$ \\
\hline 4 & $15(5.4)$ \\
\hline 5 & $7(2.5)$ \\
\hline \multicolumn{2}{|l|}{ ASA score, n (\%) } \\
\hline I-II & $272(97.8)$ \\
\hline III-IV & $6(2.2)$ \\
\hline \multicolumn{2}{|l|}{ No. side (\%) } \\
\hline Lt. & $129(46.4)$ \\
\hline Rt. & $149(53.6)$ \\
\hline Tumor size (cm), median (IQR) & $2.2(1.2-3.2)$ \\
\hline R.E.N.A.L. score, median (IQR) & $5.0(3.0-7.0)$ \\
\hline \multicolumn{2}{|l|}{ cT stage, n (\%) } \\
\hline cT1a & $258(92.8)$ \\
\hline cT1b & $20(7.2)$ \\
\hline
\end{tabular}

$I Q R$, interquartile range.

\section{Statistical analysis}

All statistical analyses were performed using IBM SPSS ${ }^{\circledR}$ 20.0. Recurrence-free survival (RFS) and overall survival (OS) curves were plotted using the Kaplan-Meier technique and compared by log-rank test. Paired $t$-tests were employed for the comparison of eGFR and $\mathrm{Hb}$ values before and after surgery. $\mathrm{P}<0.05$ was considered to indicate statistical significance.

\section{Results}

\section{Patient characteristics}

In total, 278 patients included in this research. The median patient age was 57.0 years [interquartile range (IQR), $40.0-74.0$ years] and 222 (79.9\%) of the patients were male. Patient demographics are shown in Table 1. Among them, $272(97.8 \%)$ had American Society of Anesthesiologists (ASA) scores of I or II and 6 (2.2\%) had scores of III. The median age-adjusted Charlson Comorbidity Index (aCCI) for the patients was 2.0 (IQR, 0-5). There were $258 \mathrm{cT} 1 \mathrm{a}$ patients and $20 \mathrm{cT} 1 \mathrm{~b}$ patients. The median tumor diameter was $2.2 \mathrm{~cm}$ (IQR, $0.8-7.0 \mathrm{~cm}$ ) and the median R.E.N.A.L score was 5.37 (IQR, 4-10). For cT1a patients, the median tumor diameter was $2.2 \mathrm{~cm}$ (IQR, $0.8-4.0 \mathrm{~cm}$ ) and the mean R.E.N.A.L score was 5.3 (IQR, 4-10). For cT1b patients, the median tumor diameter was $4.6 \mathrm{~cm}$ (IQR, $4.1-7.0 \mathrm{~cm}$ ) and median R.E.N.A.L score was 6.5 (IQR, 6-9).

\section{Perioperative outcomes}

The median length of operation was $86 \mathrm{~min}$ (IQR, 28.75$143.25 \mathrm{~min}$ ), and the median approximate blood loss was $50 \mathrm{~mL}$ (IQR, 22.50-77.50 mL). Moreover, in majority of patients $(\mathrm{n}=222,81.3 \%)$, tumors were clear-cell RCC according to pathologic diagnosis. In addition, 21 cases of papillary RCC and 16 cases of chromophobe RCC were diagnosed. The 15 cases of other types of malignancy comprised four cases of mucinous tubular and spindle cell carcinoma (MTASCC), one case of nephroblastoma, three cases of multilocular cystic renal neoplasm of low malignant potential (MCRNLMP) and seven cases of RCC could not be classified clearly due to post-ablation microscopic changes. Among the 278 samples, no instances of positive surgical margin were reported (Table 2).

After surgery, the post-operative complication rate was $7.6 \%(\mathrm{n}=21)$, among which $7(2.5 \%)$ cases were Clavien grade I, $9(3.2 \%)$ were grade II and 2 (1.8\%) were grade IIIa. Details of the complications and management are shown in Table 3.

\section{Oncologic outcomes}

The median follow-up period was 39 months (IQR, 23.7554.25 months). There were two local recurrences and six distal metastases. The characteristics of these patients are illustrated in Table 4. Both local recurrences occurred within 
2 years after the initial procedure and received completion radical nephrectomy. Both patients had negative surgical margins at the time of the first surgery. One of the two patients was diagnosed as Fuhrman grade II ccRCC after the first surgery and local recurrence was found 9 months after the first surgery. The patient underwent salvage radical nephrectomy, and the post-operative pathologic results was similar to those of the initial tumor. The other patient was diagnosed as de-differentiated liposarcoma (DDLS) after the first surgery and local recurrence was diagnosed 10 months later. The post-operative pathological diagnosis was also DDLS, and the patient remained alive at the time of the last follow-up without any treatment.

All six distal metastasis cases occurred at least 2 years after surgery. These patients received targeted therapy and remained alive at the latest follow-up.

In addition, a new tumor was found on the contralateral

Table 2 Perioperative outcomes of patients undergoing zero ischemia laparoscopic microwave ablation assisted tumor enucleation

\begin{tabular}{lc}
\hline Parameters & Value \\
\hline Operative time (min), median (IQR) & $86.00(28.75-143.25)$ \\
Estimated blood loss (mL), median (IQR) & $50.00(22.50-77.50)$ \\
Pathology, $\mathrm{n}(\%)$ & \\
Clear cell renal cell carcinoma & $226(81.3)$ \\
Papillary renal cell carcinoma & $21(7.6)$ \\
Chromophobe renal cell carcinoma & $16(5.8)$ \\
Other types of malignancy & $15(5.4)$ \\
\hline
\end{tabular}

kidney in one patient during follow-up. The patient underwent a second partial nephrectomy at our center. The post-operative pathology revealed that new tumor was also ccRCC, but with a different Fuhrman grade. The patient remained alive at the latest follow-up.

There were two deaths over the follow-up period; one patient died of esophageal carcinoma 17 months after surgery and one died of lymphoma 21 months after surgery. The 3- and 5-year OS was $99.3 \%$ and $98.4 \%$, respectively. Meanwhile, the 3 - and 5-year RFS was $98.2 \%$ and $95.8 \%$, respectively. The median RFS was 39.0 months (IQR, 9-72 months).

\section{Functional outcomes}

The median eGFR before and 3 months after surgery was 90.6 (IQR, 65.2-116.0) and 83.6 (IQR, 52.4$114.8) \mathrm{mL} / \mathrm{min} / 1.73 \mathrm{~m}^{2}$. The median eGFR at the latest follow-up was 87.4 (IQR, 67.7-107.1) $\mathrm{mL} / \mathrm{min} / 1.73 \mathrm{~m}^{2}$ and paired $t$-tests showed that there were no marked alterations between the preoperative, postoperative and latest eGFR $(\mathrm{P}=0.069$ and $\mathrm{P}=0.071)$. The median change in the eGFR from before surgery to the latest follow-up was $-2.82 \mathrm{~mL} / \mathrm{min} / 1.73 \mathrm{~m}^{2}$. Only one patient whose eGFR before surgery was $13.7 \mathrm{~mL} / \mathrm{min} / 1.73 \mathrm{~m}^{2}$ was diagnosed as stage 5 chronic kidney disease and started renal replacement therapy 7 months after surgery.

\section{Discussion}

NSS has become the gold standard therapy for patients

Table 3 Postoperative complications

\begin{tabular}{llll}
\hline Clavien Grade & No. cases & Complication & Comments \\
\hline 1 & 2 & Delayed bleeding & Bed rest and watch \\
& 4 & Urine leak & Keep Jackson-Pratt drain in place \\
& 1 & Confusion & Expectant management \\
2 & 2 & Wound infection & Incision, drainage, and oral antibiotics \\
& 3 & Pneumonia & Intravenous antibiotics \\
$3 \mathrm{Ba}$ & 4 & Hemorrhage & Blood transfusion \\
& 2 & Bleeding and hematuria & Blood vessel embolization under DSA \\
& 3 & Urine leak & Ureteral Double-J stent + intravenous \\
\end{tabular}

DSA, digital subtraction angiography. 
Table 4 Characteristics and management of local recurrence and metastasis cases

\begin{tabular}{|c|c|c|c|c|c|c|c|c|c|}
\hline Case & $\begin{array}{l}\text { Age (year)/ } \\
\text { sex/laterality }\end{array}$ & $\begin{array}{l}\text { Tumor size } \\
(\mathrm{cm})\end{array}$ & TNM stage & $\begin{array}{l}\text { Pathological } \\
\text { diagnosis }\end{array}$ & $\begin{array}{l}\text { Recurrence } \\
\text { time (months) }\end{array}$ & $\begin{array}{l}\text { Recurrence } \\
\text { type }\end{array}$ & $\begin{array}{l}\text { Follow-up } \\
\text { (months) }\end{array}$ & Management & $\begin{array}{l}\text { Disease } \\
\text { status }\end{array}$ \\
\hline 1 & 62/M/L & 2.0 & pT1aNOMO & $\begin{array}{l}\text { ccRCC, } \\
\text { Fuhrman III }\end{array}$ & 21 & $\begin{array}{l}\text { Bone } \\
\text { metastasis }\end{array}$ & 40 & $\begin{array}{l}\text { Target therapy } \\
+ \text { PVP }\end{array}$ & Alive \\
\hline 2 & 63/M/L & 3.5 & pT1aNOMO & $\begin{array}{l}\text { ccRCC, } \\
\text { Fuhrman I }\end{array}$ & 26 & $\begin{array}{l}\text { Lung } \\
\text { metastasis }\end{array}$ & 38 & Target therapy & Alive \\
\hline 4 & 75/M/R & 3.3 & pT1aNOMO & $\begin{array}{l}\text { ccRCC, } \\
\text { Fuhrman II }\end{array}$ & 9 & $\begin{array}{l}\text { Local } \\
\text { recurrence }\end{array}$ & 34 & $\begin{array}{l}\text { Radical } \\
\text { nephrectomy }\end{array}$ & Alive \\
\hline 5 & 63/F/R & 3.5 & pT1aNOMO & ChRCC & 20 & $\begin{array}{l}\text { Lung } \\
\text { metastasis }\end{array}$ & 37 & Target therapy & Alive \\
\hline 9 & $54 / F / R$ & 2.0 & pT1aNOMO & $\begin{array}{l}\text { ccRCC, } \\
\text { Fuhrman I }\end{array}$ & 35 & $\begin{array}{l}\text { Lung } \\
\text { metastasis }\end{array}$ & 66 & Target therapy & Alive \\
\hline
\end{tabular}

ccRCC, clear cell renal cell carcinoma; ChRCC, chromophobe renal cell carcinoma; MCN, multilocular cystic nephroma; DDLS, de-differentiate liposarcoma; M. male; F, female; L, left; R, right.

with cT1aN0M0 and selected T1bN0M0 renal tumors (2). Compared with radical nephrectomy, the NSS technique can both protect more renal function and achieve similar oncologic outcomes (16). However, warm ischemia caused by clamping of renal artery damages renal function (17). Thus, attempts have been made to achieve zero ischemia NSS. Minimally invasive techniques including RFA, MWA and cryoablation have been widely applied to the treatment of small renal masses worldwide. As Jacomides et al. reported in 2003, RFA-assisted laparoscopic NSS achieved favorable hemostasis and oncological outcomes (6), which was in accordance the results of several other studies.

Our center has applied RFA- and MWA-assisted LPN in patients with renal tumors since 2011. In 2016, we reported a randomized clinical trial comparing zero ischemia laparoscopic RFA-TE and LPN for cT1a renal tumors, and we found RFA-assisted tumor enucleation was superior in terms of preservation of renal function compared with conventional LPN (7). Furthermore, in our previous comparison of short-term clinical outcomes of MWA-TE and RFA-TE in cT1aNOM0 RCC patients, we found that there were no significant differences in complication rate and short-term oncological outcomes, although MWA-TE was associated with the benefits of shorter median length of operation and less estimated blood loss (18). Similar outcomes were also reported for cT1bN0M0 RCC patients treated at our center (8). However, there is still a lack of large volume studies that reveal the mid-to-long term oncologic and functional outcomes of MWA-TE. Thus, the current study was conducted as the largest sample volume and mid-to-long term single-center study of MWA-assisted tumor enucleation in patients with renal tumors.

Zero ischemia NSS can be achieved using the MWATE technique by placement of the MWA electrode to create a relatively avascular plane. MWA causes coagulated cell necrosis by inducing friction of water molecules (19). Compared to RFA, MWA is more effective for the ablation of larger tumors due to its heat generation mechanism. Yu et al. compared the efficiency of MWA and RFA in ex vivo and in vivo porcine livers and reported that MWA generated considerably higher tissue temperature $5 \mathrm{~mm}$ from the needle and that MWA produced a markedly elevated rate of temperature increase to $54{ }^{\circ} \mathrm{C}$ (when complete necrosis can be obtained) and a markedly substantial ablation area than RFA $(20,21)$. In clinical practice, we found that MWA provides the following advantages of higher intratumoral temperature and higher tissue ablation volume within a shorter ablation cycle compared to RFA. In 2007, Lane et al. 
reported a 3-year cancer-specific survival of $99.3 \%$ and RFS of $97.7 \%$ in a study of $514 \mathrm{LPN}$ patients (22). In a 3-year follow-up of 100 patients who underwent LPN, Moinzadeh et al. reported OS of $86 \%$, cancer-specific survival of $100 \%$ and RFS of $100 \%$ (23).

Here, we retrospectively analyzed the post-operative, oncologic and functional outcomes of zero ischemia laparoscopic MWA-TE. Of the 278 patients who received zero ischemia MWA-TE, the 3- and 5-year OS was $99.3 \%$ and $98.4 \%$, respectively, and the 3 - and 5-year RFS was $98.2 \%$ and $95.8 \%$, respectively, which were similar to the studies mentioned previously.

In a meta-analysis of renal function outcomes of several treatments, Patel et al. found that the median followup eGFR of PN was 71.1 in 26 studies containing 4,080 patients and the median change in eGFR was -7.4 in 27 studies containing 4,098 patients (24). In this study, we found a median follow-up eGFR of $87.4 \mathrm{~mL} / \mathrm{min} / 1.73 \mathrm{~m}^{2}$ and a median alteration in eGFR of $-2.82 \mathrm{~mL} / \mathrm{min} / 1.73 \mathrm{~m}^{2}$, which may indicate a better preservation of renal function than PN. During the follow-up period, only one patient with poor preoperative renal function received hemodialysis 7 months after surgery. Although the paired $t$-test showed that there were no significant differences between preoperative, post-operative and latest eGFR $(\mathrm{P}=0.069$ and $\mathrm{P}=0.071$ ), there was still slight decrease in $\mathrm{eGFR}$ after surgery, which indicates an inevitable decrease in renal function after surgery, probably caused by thermal damage to the peri-tumoral renal parenchyma.

Zhao et al. reported that thermal ablation-assisted tumor enucleation was accompanied by lower rate of perioperative complications, shorter hospital stays $(25,26)$. The outcomes of the current study were similar with the exception of a lower rate of post-operative urine leakage, which can be ascribed to the strict indication criteria for the technique applied in our center. Cases in which the tumor involved the collecting system were excluded from our study, thus patients who underwent thermal ablation-assisted tumor enucleation may have lower R.E.N.A.L scores (mean $=5.37$, ranging from 4 to 10), that is, there was more exogenously growth of the tumor in these patients. In our study, the intra-operative blood loss was $50 \mathrm{~mL}$, which is lower than that reported by Zhao. This may be due to the complete ablation of the tumor bed before enucleation, which results in minimization of the number of cases of bleeding during enucleation and when it does occur, this is easily controlled by bipolar or unipolar electric coagulation.

Although Clark et al. demonstrated that ablation did not affect the post-operative pathological diagnosis (27), our study included seven cases with an unclear post-operative pathological diagnosis due to the complete ablation of the tumor components.

Several groups have demonstrated that biopsy is necessary for follow-up after ablation. The MWA-TE technique provides the additional benefit that in patients undergoing pure percutaneous microwave/RFA for RCCs, local focal recurrence can be detected by contrast-enhanced CT scans performed at every follow-up. This avoids the need for an invasive operation that may cause tumor dissemination along the biopsy needle path. Moreover, pure ablation has a higher rate of local recurrence than tumor enucleation or partial nephrectomy $(4,28)$. On this bias, the MWA-TE technique combines the advantages of both MWA and TE.

Here, we report oncological and functional consequences after mid-to-long term follow-up of 278 patients who received MWA-TE in our institution. This study is the first large volume study providing the mid-to-long term followup results for MWA-TE. Nevertheless, the limitations of this study should be noted. First, this retrospective study involved only single-center, and is therefore, is associated with all the shortcomings of this study design, including the lack of randomization and control group. Second, here, we only overviewed the consequences of MWA-TE patients and did not include a control group comparing results of pure TE or RFA-LPN.

\section{Conclusions}

In conclusion, zero ischemia laparoscopic MWA-TE is considered a safe and effective nephron sparing surgical technique for selected renal tumors, and is accompanied by promising mid-to-long term oncological and functional outcomes, as well as a low perioperative complication rate.

\section{Acknowledgments}

Funding: This study received funding from the ThreeYear-Action-Project (No: 16CR3062B) of Shanghai Shen Kang Hospital Development Center, the MedicalEngineering cross fund of Shanghai Jiao Tong University (No. YG2017QN46), and the National Natural Science Foundation of China (No. 81972369).

\section{Footnote}

Reporting Checklist: The authors have completed the 
STROBE reporting checklist. Available at http://dx.doi. org/10.21037/tcr-20-2846

Data Sharing Statement: Available at http://dx.doi. org/10.21037/tcr-20-2846

Peer Review File: Available at http://dx.doi.org/10.21037/tcr20-2846

Conflicts of Interest: All authors have completed the ICMJE uniform disclosure form (available at http://dx.doi. org/10.21037/tcr-20-2846). The authors have no conflicts of interest to declare.

Ethical Statement: The authors are accountable for all aspects of the work in ensuring that questions related to the accuracy or integrity of any part of the work are appropriately investigated and resolved. The study was conducted in accordance with the Declaration of Helsinki (as revised in 2013). The study was approved by research medical ethics committee of Shanghai Renji Hospital, China (Ethics board approval number: Renji Ethics [2017]091). Informed consent was obtained from all individual participants.

Open Access Statement: This is an Open Access article distributed in accordance with the Creative Commons Attribution-NonCommercial-NoDerivs 4.0 International License (CC BY-NC-ND 4.0), which permits the noncommercial replication and distribution of the article with the strict proviso that no changes or edits are made and the original work is properly cited (including links to both the formal publication through the relevant DOI and the license). See: https://creativecommons.org/licenses/by-nc-nd/4.0/.

\section{References}

1. Escudier B, Porta C, Schmidinger M, et al. Renal cell carcinoma: ESMO Clinical Practice Guidelines for diagnosis, treatment and follow-up. Ann Oncol 2016;27:v58-68.

2. Ljungberg B, Albiges L, Abu-Ghanem Y, et al. European Association of Urology Guidelines on Renal Cell Carcinoma: The 2019 Update. Eur Urol 2019;75:799-810.

3. Hung AJ, Cai J, Simmons MN, et al. "Trifecta" in partial nephrectomy. J Urol 2013;189:36-42.

4. Filippiadis D, Mauri G, Marra P, et al. Percutaneous ablation techniques for renal cell carcinoma: current status and future trends. Int J Hyperthermia 2019;36:21-30.

5. Zhang S, Wu S, Shang S, et al. Detection and Monitoring of Thermal Lesions Induced by Microwave Ablation Using Ultrasound Imaging and Convolutional Neural Networks. IEEE J Biomed Health Inform 2020;24:965-73.

6. Jacomides L, Ogan K, Watumull L, et al. Laparoscopic application of radio frequency energy enables in situ renal tumor ablation and partial nephrectomy. J Urol 2003;169:49-53.

7. Huang J, Zhang J, Wang Y, et al. Comparing Zero Ischemia Laparoscopic Radio Frequency Ablation Assisted Tumor Enucleation and Laparoscopic Partial Nephrectomy for Clinical T1a Renal Tumor: A Randomized Clinical Trial. J Urol 2016;195:1677-83.

8. Chen Y, Wu X, Zhou J, et al. Thermal ablation assisted laparoscopic partial nephrectomy for clinical $\mathrm{T} 1 \mathrm{~b}$ renal tumors. Minim Invasive Ther Allied Technol 2020. [Epub ahead of print]. doi:10.1080/13645706.2020.1780451.

9. Muto G, Castelli E, Migliari R, et al. Laparoscopic microwave ablation and enucleation of small renal masses: preliminary experience. Eur Urol 2011;60:173-6.

10. Choi SH, Kim JW, Kim JH, et al. Efficacy and Safety of Microwave Ablation for Malignant Renal Tumors: An Updated Systematic Review and Meta-Analysis of the Literature Since 2012. Korean J Radiol 2018;19:938-49.

11. Kutikov A, Uzzo RG. The R.E.N.A.L. nephrometry score: a comprehensive standardized system for quantitating renal tumor size, location and depth. J Urol 2009;182:844-53.

12. Dindo D, Demartines N, Clavien PA. Classification of surgical complications: a new proposal with evaluation in a cohort of 6336 patients and results of a survey. Ann Surg 2004:240:205-13.

13. Scoazec JY, Sabourin JC. 2010: The seventh edition of the TNM classification. Ann Pathol 2010;30:2-6.

14. Fuhrman SA, Lasky LC, Limas C. Prognostic significance of morphologic parameters in renal cell carcinoma. Am J Surg Pathol 1982;6:655-63.

15. Levey AS, Stevens LA, Schmid CH, et al. A new equation to estimate glomerular filtration rate. Ann Intern Med 2009;150:604-12.

16. Ng AM, Shah PH, Kavoussi LR. Laparoscopic Partial Nephrectomy: A Narrative Review and Comparison with Open and Robotic Partial Nephrectomy. J Endourol 2017;31:976-84.

17. Lee H, Song BD, Byun SS, et al. Impact of warm ischaemia time on postoperative renal function after partial nephrectomy for clinical T1 renal cell carcinoma: a 
propensity score-matched study. BJU Int 2018;121:46-52.

18. Wu X, Chen W, Chen Y, et al. Comparison of laparoscopic microwave ablation and radio frequency ablation assisted renal tumor enucleation for renal tumor smaller than 4 cm. Chinese Journal of Urology 2016;37:12-6.

19. McCarthy CJ, Gervais DA. Decision Making: Thermal Ablation Options for Small Renal Masses. Semin Intervent Radiol 2017;34:167-75.

20. Liang P, Wang Y. Microwave ablation of hepatocellular carcinoma. Oncology 2007;72:124-31.

21. Yu J, Liang P, Yu X, et al. A comparison of microwave ablation and bipolar radiofrequency ablation both with an internally cooled probe: results in ex vivo and in vivo porcine livers. Eur J Radiol 2011;79:124-30.

22. Lane BR, Gill IS. 5-Year outcomes of laparoscopic partial nephrectomy. J Urol 2007;177:70-4; discussion 74.

23. Moinzadeh A, Gill IS, Finelli A, et al. Laparoscopic partial nephrectomy: 3-year followup. J Urol 2006;175:459-62.

24. Patel HD, Pierorazio PM, Johnson MH, et al. Renal

Cite this article as: Zhou $\mathrm{J}, \mathrm{Wu} \mathrm{X}$, Zhang J, Huang J, Chen Y. Mid-to-long term oncologic and functional outcomes of zero ischemia laparoscopic microwave ablation-assisted tumor enucleation for renal cell carcinoma: a single-center experience. Transl Cancer Res 2021;10(5):2328-2336. doi: 10.21037/tcr-202846
Functional Outcomes after Surgery, Ablation, and Active Surveillance of Localized Renal Tumors: A Systematic Review and Meta-Analysis. Clin J Am Soc Nephrol 2017;12:1057-69.

25. Zhao X, Zhang S, Liu G, et al. Zero ischemia laparoscopic radio frequency ablation assisted enucleation of renal cell carcinoma: experience with 42 patients. J Urol 2012;188:1095-101.

26. Zhang C, Zhao X, Guo S, et al. Perioperative outcomes of zero ischemia radiofrequency ablation-assisted tumor enucleation for renal cell carcinoma: results of 182 patients. BMC Urol 2018;18:41.

27. Clark PE, Woodruff RD, Zagoria RJ, et al. Microwave ablation of renal parenchymal tumors before nephrectomy: phase I study. AJR Am J Roentgenol 2007;188:1212-4.

28. Finelli A, Ismaila N, Bro B, et al. Management of Small Renal Masses: American Society of Clinical Oncology Clinical Practice Guideline. J Clin Oncol 2017;35:668-80. 